\title{
INFLUENCE OF P-GLYCOPROTEIN AND CYTOCHROME ISOENZYME-P3A4 ON BIOAVAILABILITY OF ANTICANCER DRUGS WITH CURCUMIN BY IN SITU INTESTINAL PERFUSION IN MALE WISTAR RATS
}

\author{
MANOJ KANNA NALLA, SHANKARAIAH PULIGILLA*
}

Department of Pharmacology, Chaitanya College of Pharmacy Education and Research, Kishanpura, Hanamkonda, Telangana, India. Email: drspuligilla@gmail.com

Received: 06 March 2019, Revised and Accepted: 22 May 2019

Objectives: An orally administered anticancer drug has been poor drug absorption; drug resistance and metabolism, which alters the bioavailability of drugs. An in situ intestine perfusion technique is developing under the different perfusion rates in the presence of drug inducers and inhibitors of cytochrome isoenzyme-P (CYP)-3A4 and P-glycoprotein (P-gp) for drug concentrations.

Materials and Methods: The modified in situ intestinal perfusion technique was developed and followed to obtain the portal and hepatic venous blood samples paralleled at different perfusion time and flow rates of $0.05,0.1,0.5$, and $1.0 \mathrm{~mL} / \mathrm{min}$ using the imatinib $(1 \mathrm{mg} / \mathrm{mL}) \mathrm{drug}$ alone and in the presence of drug inducer and drug inhibitor for the period of $3 \mathrm{~h}$. The imatinib drug concentrations were assayed using high-pressure liquid chromatography.

Results: The results reveal that the mean imatinib drug concentrations in portal vein were higher than hepatic vein at various perfusion flow rates and time intervals were observed. The area under curve and plasma drug concentrations maximum of imatinib alone absorptions were significantly different between portal and hepatic veins $(\mathrm{p}<0.05)$ at the flow rates of 0.5 and $1.0 \mathrm{~mL} / \mathrm{min}$ and also in the presence of drug inducer and inhibitors that indicating for the considerable hepatic involvement in the presystemic extraction or metabolism of drugs.

Conclusions: The in situ perfusions approach could provide the useful tool for improving the basic understanding of absorption kinetics and hepatic metabolism of drugs in the presence of drug inducers and drug inhibitors (CYP3A4 and P-gp) under the development and facilitating the clinical applications.

Keywords: P-glycoprotein, Cytochrome isoenzyme-P3A4, Drug absorption, Imatinib, Intestinal perfusion.

(c) 2019 The Authors. Published by Innovare Academic Sciences Pvt Ltd. This is an open access article under the CC BY license (http://creativecommons. org/licenses/by/4. 0/) DOI: http://dx.doi.org/10.22159/ajpcr.2019.v12i7.32938

\section{INTRODUCTION}

Oral administered drugs have been more convenient, easy, and high patient compliance. The different dosage forms of drugs were altered the pharmacokinetic and pharmacodynamic parameters [1]. The less oral bioavailability of drugs may be affected of drug metabolism by cytochrome isoenzyme-P (CYP)-450 enzymes family and other drug efflux transporter proteins of P-glycoprotein (P-gP) [2]. If the administered drugs may not be reached into the systemic circulation until the large doses were given, the natural bioenhancers or plantbased molecules were reduced the risk of drug resistance, rapid metabolism of drugs, and minimize the drug toxicity and they can improve the oral bioavailability $[3,4]$.

The oral bioavailability of imatinib drug always depends on the transporter proteins of P-gP and metabolic enzyme of CYP3A4. The pharmacokinetics area under curve (AUC) of imatinib was affects when coadministered with the drug inducer and inhibitors [5-7], but the imatinib anticancer effect was depended on the plasma concentrations of drug [8-10]. Curcumin is a natural phytochemical have been multifunctional agent, which is also reduce the risk of cancer; therefore, in the combination of curcumin with imatinib can improve the pharmacokinetics and pharmacodynamic parameters of the drug [11]. The transportation of drug molecules and across the cell membrane and reached into the blood was also important aspect of drug absorption and plasma concentrations of the drug $[12,13]$. The herbal drugs have been playing a major role an effect on drug absorption, drug metabolism, and drug transporters functions such as P-gP and CYP3A4. In this study, we investigated the effects of curcumin on drug absorption and drug metabolism in the presence of drug inducers and drug inhibitors.

\section{MATERIALS AND METHODS}

Male Wister rats were selected and weighed about 150-250 g, obtained from Sainath Agencies, Hyderabad, India. They were housed in cages at a room temperature around $20-22^{\circ} \mathrm{C}$ and $12 \mathrm{~h}$ day-night light cycle, all animals were free access to water and feed, then used for experimental study after acclimatization period and approval of the study protocol by the Institutional Animal Ethics Committee of the Viswabharati Education Society (CPCSEA/VBES/001/2017), Kishanpura, Warangal, Telangana State, India.

The study design as follows: All rats were divided into three groups $(n=6)$.

- Group I: Treated with imatinib only (CYP3A4 and P-gp substrate)

- Group II: Curcumin pretreated $1 \mathrm{~h}$ before the study with imatinib (perfusion studies) (CYP3A4 and P-gp inhibitor)

- Group III: Phenytoin pretreated was coadministered along with buffer containing imatinib $(100 \mu \mathrm{g} / \mathrm{mL})$ (CYP3A4 and P-gp inducer).

In situ single-pass intestinal perfusion

The perfusion technique procedure was followed from $\mathrm{Yu}$ et al. with the minor modifications, as rats were fasted $16 \mathrm{~h}$ before the perfusion study; all the rats were anesthetized with $3.5 \%$ pentobarbital solution $(1 \mathrm{~mL} / \mathrm{kg}$, i.p.) and made a gentle midline incision. $15 \mathrm{~cm}$ small intestine region was selected for inlet at the proximal end of duodenum and outlet was at the distal end of ileum; they were tied with the cannulation 
tubes. Before perfusion of the drugs, the intestinal lumen was cleaned with isotonic saline; then, the inlet perfusion tube was filled and perfused by warmed $\left(37^{\circ} \mathrm{C}\right)$ imatinib drug solution alone and followed in the presence of curcumin, phenytoin at the flow rates of $0.05,0.1$, 0.5 , and $1.0 \mathrm{~mL} / \mathrm{min}$ using with a peristaltic perfusion pump. The first few minutes of drug perfusion period were set as the lag time period and the collection of blood samples was initiated after the lag period, during the experiment, the intestine was covered and moistened with cotton gauze of warm saline $\left(37^{\circ} \mathrm{C}\right)$ and also kept it for warming effect over the small intestine using the small lamp was placed throughout the experiment [14].

\section{Pharmacokinetic studies and sample preparation}

The blood samples were collected as per the study designs of Kukan's liver perfusion procedure [15] and using the intravenous (i.v.) catheters for sampling of portal and hepatic venous blood, they were, 24-gauge i.v. catheter was inserted into the portal vein and 18-gauge i.v. catheter was inserted into the junction of the hepatic vein and also collected the samples from intestine perfusate. At the end of the lag time, $0.4 \mathrm{~mL}$ of blood sample was drawn using with alternate syringes from both catheters over a period of $3 \mathrm{~h}$ at the time intervals of $0,5,15,30,60,90120$, and 180 min then centrifuged the blood samples at $3000 \mathrm{~g}$ for $15 \mathrm{~min}$ at $4^{\circ} \mathrm{C}$, plasma samples were separated and modified for high-performance liquid chromatography (HPLC) analysis. The plasma samples were taken in to clean and dry $2 \mathrm{~mL}$ Eppendorf tubes and added the $200 \mu \mathrm{L}$ of acetonitrile, $150 \mu \mathrm{L}$ of internal standard solution then vigorously shaken for $5 \mathrm{~min}$ and centrifuged at $2500 \mathrm{rpm}$ for $10 \mathrm{~min}$ at $4^{\circ} \mathrm{C}$ using with cooling centrifuge. The upper organic layer was transferred to a clean tube and evaporated at room temperature. The residue was dissolved in $500 \mu \mathrm{L}$ of the mobile phase $(50 \mathrm{mM}$ phosphate buffer pH 3.5/acetonitrile: $60 / 40 \%$ ) and $3 \mathrm{~mL}$ of $n$-hexane. The dissolved sample was vortexed for $5 \mathrm{~min}$ and then centrifuged $\left(4^{\circ} \mathrm{C}, 12,000 \mathrm{~g}\right.$, and $10 \mathrm{~min}$ ). The upper organic layer was discarded and the eluent was used for HPLC analysis of imatinib.

\section{RESULTS}

The results of portal, hepatic plasma, and intestinal perfusate drug concentrations of imatinib $(1 \mathrm{mg} / \mathrm{mL})$ were obtained by in situ single-pass intestinal perfusion technique under the four different flow rates $(0.05,0.1,0.5$, and $1.0 \mathrm{~mL} / \mathrm{min})$ and $3 \mathrm{~h}$ time intervals. The mean imatinib alone and in the presence of curcumin, the drug concentrations were significantly $(\mathrm{p}<0.001)$ higher in portal vein and in intestinal perfusate than in the hepatic veins, which indicate that the presystemic metabolism of imatinib in the liver is considerable. In the presence of drug inducer (phenytoin), plasma imatinib concentrations were very low at various flow rates compared with the P-gp and CYP inhibitor (curcumin) at different time points. At the $1.0 \mathrm{~mL} / \mathrm{min}$ flow rate of imatinib, perfusate was observed the very low concentrations of the two venous groups and intestine perfusate was significantly different $(p<0.05)$ at all-time points of the study.

The pharmacokinetics were extended $\left(\mathrm{AUC}_{0-3 \mathrm{~h}}\right)$ and the maximal plasma concentrations $\left(\mathrm{C}_{\max }\right)$ of imatinib absorption between the portal, hepatic venous, and intestinal perfusate groups were significantly different in the presence of the druginducers and inhibitors $\left(\mathrm{AUC}_{0-3 \mathrm{~h}}=4796.32 \pm 216.7 \mathrm{vs}\right.$. $6127.35 \pm 211.9 \mu \mathrm{g} / \mathrm{min} / \mathrm{mL} ; \quad C_{\max }=43 \pm 2.3$ vs. $76 \pm 2.5 \mu \mathrm{g} / \mathrm{mL}$, $\mathrm{AUC}_{0-3 \mathrm{~h}}=2987.76 \pm 121.76$ vs. $4756.34 \pm 176.4 \mu \mathrm{g} / \mathrm{min} / \mathrm{mL} ; \mathrm{C}_{\max }=$ $24 \pm 3.5$ vs. $40 \pm 3.3 \mu \mathrm{g} / \mathrm{mL}, \mathrm{AUC}_{0-3 \mathrm{~h}}=8070.66 \pm 23.68$ vs. $1205.98 \pm 33.65$; $\mathrm{C}_{\max }=71 \pm 5.32$ vs. $\left.105 \pm 13.9\right)(\mathrm{p}<0.05)$ (Tables $\left.1-3\right)$. The results were evaluated using linear trapezoidal method. Further, comparative analyses of $\mathrm{AUC}_{0-3 \mathrm{~h}^{\prime}}$ within both portal and hepatic groups the absorption process were seemed to differ that lower $\mathrm{C}_{\text {max }}$ due to higher flow rates (Fig. 1a) and longer $\mathrm{T}_{\max }$ (Fig. 1b) were observed, in addition also increased the $\mathrm{AUC}_{0-3 \mathrm{n}}$ (Fig. 1c). The absolute bioavailability was correlated inversely with perfusion flow rates and time period, the high amount of drug absorptions was taken place at lower flow rates and long duration and also depends on drug inducers and drug inhibitors.

\section{DISCUSSION}

An in situ intestinal drug perfusion method may provide the best to understand the absorption of the drugs which is very close to intact blood circulation may increase the drug uptake and drug metabolites disposals [16]. The blood drawing through jejunal vein is to determine the drug absorptions $[17,18]$ and the first-pass metabolism in the liver as well as in the intestine $[19,20]$. It is known as the drug metabolizing enzyme cytochrome P450 located in the liver and the P-gp transporter proteins present in the intestine, liver, lungs, and cardiovascular

Table 1: Pharmacokinetic parameters of imatinib after in situ single-pass intestinal perfusion of imatinib (1 $\mathrm{mg} / \mathrm{min})$ to anesthetized rats in the presence of cytochrome isoenzyme-P3A4, P-glycoprotein drug inducers, and inhibitors in portal vein

\begin{tabular}{llll}
\hline Pharmacokinetics & Portal vein concentrations & \\
\cline { 2 - 4 } & $\begin{array}{l}\text { Phenytoin+imatinib } \\
\text { (Mean } \pm \text { SD) }\end{array}$ & $\begin{array}{l}\text { Imatinib } \\
\text { (Mean } \pm \text { SD) }\end{array}$ & $\begin{array}{l}\text { Curcumin+imatinib } \\
\text { (Mean } \pm \text { SD) }\end{array}$ \\
\hline $\mathrm{C}_{\text {max }}(\mu \mathrm{g})$ & $43 \pm 2.3$ & $53 \pm 2.4$ & $62 \pm 3.1^{*}$ \\
$\mathrm{~T}_{\max }(\mathrm{min})$ & $120 \pm 8.4$ & $120 \pm 9.2$ & $120 \pm 12.1$ \\
$\mathrm{AUC}_{0-3 \mathrm{~h}}$ & $4796.32 \pm 216.7$ & $4509.5 \pm 341.9$ & $6127.35 \pm 211.9^{*}$ \\
$\mathrm{AUC}_{0-\mathrm{inf}}$ & $4824.48 \pm 436.8$ & $4665.3 \pm 216.3$ & $6469.87 \pm 362.8^{*}$ \\
$\mathrm{t}_{1 / 2}$ & 2.0 & 1.9 & 1.9 \\
\hline
\end{tabular}

${ }^{*} \mathrm{p}<0.05$ represents that statistically significant results when compared with drug inducers and inhibitors ( $\left.\mathrm{n}=6\right)$. AUC: Area under curve

Table 2: Pharmacokinetic parameters of imatinib after in situ single-pass intestinal perfusion of imatinib (1 mg/min) to anesthetized rats in the presence of cytochrome isoenzyme-P, P-glycoprotein drug inducers, and inhibitors in hepatic vein

\begin{tabular}{|c|c|c|c|c|}
\hline \multirow[t]{2}{*}{ Pharmacokinetics } & \multicolumn{4}{|c|}{ Hepatic vein concentrations } \\
\hline & $\begin{array}{l}\text { Phenytoin+imatinib } \\
\text { (Mean } \pm \text { SD) }\end{array}$ & $\begin{array}{l}\text { Imatinib } \\
\text { (Mean } \pm S D)\end{array}$ & $\begin{array}{l}\text { Curcumin+imatinib } \\
(\text { Mean } \pm \text { SD) }\end{array}$ & $\begin{array}{l}\text { Verapamil+imatinib } \\
(\text { Mean } \pm \text { SD) }\end{array}$ \\
\hline $\mathrm{C}_{\max }(\mu \mathrm{g})$ & $24 \pm 3.5$ & $26 \pm 2.1$ & $34 \pm 3.8^{*}$ & $40 \pm 3.3^{* *}$ \\
\hline $\mathrm{T}_{\max }^{\max }(\min )$ & $90 \pm 7.54$ & $90 \pm 8.43$ & $120 \pm 8.33^{*}$ & $120 \pm 9.12^{*}$ \\
\hline $\mathrm{AUC}_{0-3 \mathrm{~h}}$ & $2987.76 \pm 121.76$ & $3438.89 \pm 223.71$ & $3657.87 \pm 134.52 *$ & $4756.34 \pm 176.4^{* *}$ \\
\hline $\mathrm{AUC}_{0-\mathrm{inf}}$ & $3056.98 \pm 326.2$ & $3475.18 \pm 231.4$ & $3754.54 \pm 213.9 *$ & $4818.65 \pm 231.3^{* *}$ \\
\hline
\end{tabular}


Table 3: Pharmacokinetic parameters of imatinib after in situ single-pass intestinal perfusion of imatinib (1 mg/min) to anesthetized rats in the presence of cytochrome isoenzyme-P, P-glycoprotein drug inducers, and inhibitors in intestinal perfusate concentrations

\begin{tabular}{llll}
\hline Pharmacokinetics & \multicolumn{2}{l}{ Intestinal perfusate concentrations } \\
\cline { 2 - 4 } & $\begin{array}{l}\text { Phenytoin+imatinib } \\
\text { (Mean } \pm \text { SD) }\end{array}$ & $\begin{array}{l}\text { Imatinib } \\
\text { (Mean } \pm \text { SD) }\end{array}$ & $\begin{array}{l}\text { Curcumin+imatinib } \\
\text { (Mean } \pm \text { SD) }\end{array}$ \\
\hline $\mathrm{C}_{\max }(\mu \mathrm{g})$ & $71 \pm 5.32$ & $88 \pm 6.4^{*}$ & $94 \pm 7.5^{*}$ \\
$\mathrm{~T}_{\max }(\mathrm{min})$ & $120 \pm 6.45$ & $120 \pm 28.4$ & $120 \pm 19.6$ \\
$\mathrm{AUC}_{0-3 \mathrm{~h}}$ & $8070.66 \pm 23.68$ & $9856.55 \pm 45.87^{*}$ & $1133.45 \pm 56.32^{*}$ \\
$\mathrm{AUC}_{0-\text { inf }}$ & $8142.76 \pm 34.6$ & $1043.77 \pm 64.37^{*}$ & $1164.66 \pm 78.31^{*}$ \\
$\mathrm{t}_{1 / 2}(\mathrm{~h})$ & 1.9 & 1.9 & 2.1 \\
\hline
\end{tabular}

${ }^{* *} \mathrm{p}<0.01$ and ${ }^{*} \mathrm{p}<0.05$ represent that statistically significant results when compared with drug inducers and inhibitors ( $\left.\mathrm{n}=6\right)$. AUC: Area under curve

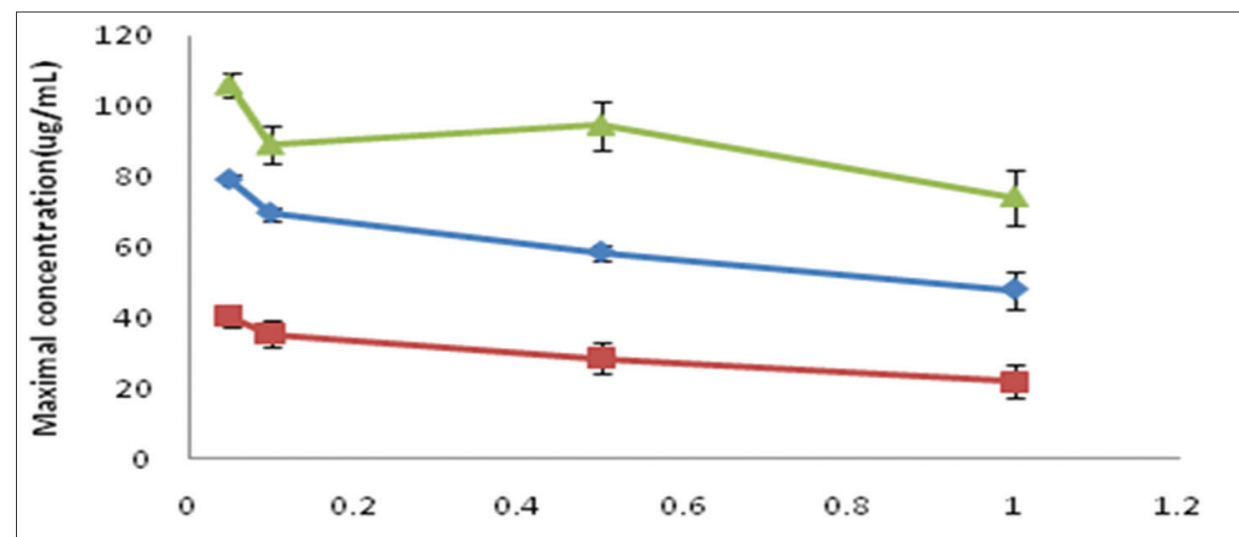

a
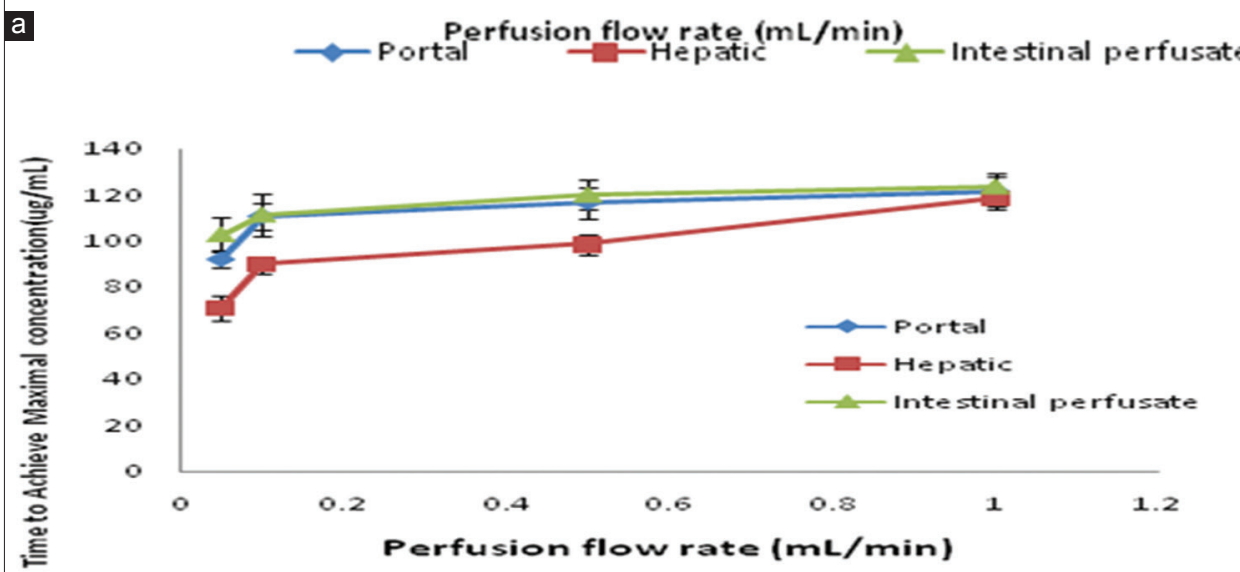

b

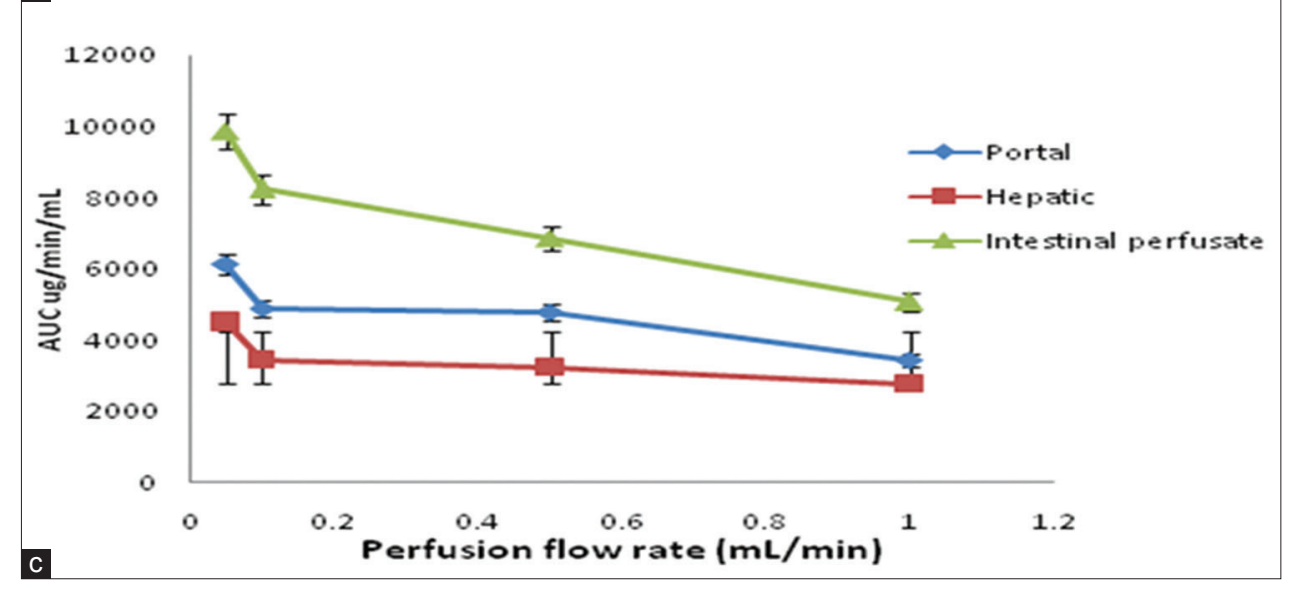

Fig. 1: (Mean \pm standard deviation) Comparison of portal, hepatic, and intestinal perfusions at the junction of the hepatic vein, intestinal perfusate, and inferior vena cava; (a) maximal plasma concentration, (b) time to achieve maximal concentration, and (c) area under the curve at different perfusion flow rates by in situ single-pass intestinal perfusion of imatinib (1 $\mathrm{mg} / \mathrm{min}$ ) during the $3-\mathrm{h}$ study in rats. *Pre- and post-hepatic values were significantly different at the designated flow rates $(\mathrm{p}<0.05$, paired $\mathrm{t}$-test). Results are given as mean \pm standard deviation $(n=6)$ 
systems, in our results, the curcumin coadministration is modulated the metabolizing enzyme CYP3A4 and efflux drug transporters P-gP expressions in liver and intestine and increased the bioavailability of imatinib, which reveals the previous study reports [21,22]. The results represent that the hepatic vein plasma concentration is lower than the jugular blood vessel plasma concentrations, which indicates the first-pass metabolism of drugs $[23,24]$ and controlled the extrahepatic systemic metabolism of imatinib during the movement between the hepatic vein and other blood collecting sites, due to in the presence of curcumin. Imatinib is an anticancer drug characterized to metabolized by CYP3A4 and efflux in intestine due to the P-gP transporters, the present study executes that imatinib is administered in the presence of curcumin could control the drug metabolism and drug resistance, which can increase the AUC and $\mathrm{C}_{\text {max }}$, due to the drug inhibitor effect of curcumin, which is support to the previous reports of Zhang et al. [25]. This study result reveals that the flow rate and duration of the perfusions can affect on plasma concentration of imatinib and the drug absorption was improved from rat intestine with curcumin coadministration. The approaches described in this study will be a useful tool for improving the drug absorption kinetics [26,27].

The herbs also used in the treatment of cancer, they contain antioxidants and flavonoids having multifunctional properties and easily available in nature [28]

\section{CONCLUSIONS}

Using in situ single-pass intestinal perfusion combined with direct sampling of portal and hepatic venous blood, to evaluate the function of drug perfusion flow rate, duration, and the presence of drug inducers and drug inhibitors, the respective plasma concentration-time profiles of imatinib absorption were improved in the presence of curcumin from rat intestine. This study is useful for understanding the drug absorption and metabolism.

\section{ACKNOWLEDGMENTS}

The authors are thankful to the Science and Engineering Research Board (SERB) New Delhi. Govt. of India, for their financial assistance Under Start Up Research Grant (Young Scientist).

\section{AUTHORS' CONTRIBUTIONS}

Manoj Kanna Nalla contributed to the experimentation, manuscript writing, and analysis.

Shankaraiah Puligilla was involved in research planning, manuscript writing, and supervision.

\section{CONFLICTS OF INTEREST}

Authors declare that there are no conflicts of interest.

\section{REFERENCES}

1. Agoram B, Woltosz WS, Bolger MB. Predicting the impact of physiological and biochemical processes on oral drug bioavailability. Adv Drug Deliv Rev 2001;50 Suppl 1:S41-67.

2. Somar M, Crowe A, Hughes J. Distribution of the single nucleotide polymorphism c3435t of mdrlgene among people in Western Australia, Australia. Int J Pharm Pharm Sci 2013;5:470-3.

3. Shailendra W, Sarita S, Swati R. Bioavailability enhancement by piperine: A review. Asian J Biomed Pharm Sci 2014;4:1-8.

4. Hermann R, von Richter O. Clinical evidence of herbal drugs as perpetrators of pharmacokinetic drug interactions. Planta Med 2012;78:1458-77.

5. Van Erp NP, Gelderblom H, Karlsson MO. Influence of CYP3A4 inhibition on the steady-state pharmacokinetics of imatinib. Clin Cancer Res 2007; 13:7394-400.

6. Gschwind HP, Pfaar U, Waldmeier F, Zollinger M, Sayer C, Zbinden P, et al. Metabolism and disposition of imatinib mesylate in healthy volunteers. Drug Metab Dispos 2005;33:1503-12.

7. Peng B, Lloyd P, Schran H. Clinical pharmacokinetics of imatinib. Clin Pharmacokinet 2005;44:879-94.

8. Frye RF, Fitzgerald SM, Lagattuta TF, Hruska MW, Egorin MJ. Effect of St John's wort on imatinib mesylate pharmacokinetics. Clin Pharmacol Ther 2004;76:323-9.

9. Cortes JE, Egorin MJ, Guilhot F, Molimard M, Mahon FX. Pharmacokinetic/pharmacodynamic correlation and blood-level testing in imatinib therapy for chronic myeloid leukemia. Leukemia 2009;23:1537-44.

10. Scott LM, Durant P, Leone-Kabler S, Wood CE, Register TC, Townsend A, et al. Effects of prior oral contraceptive use and soy isoflavonoids on estrogen-metabolizing cytochrome P450 enzymes. J Steroid Biochem Mol Biol 2008;112:179-85.

11. Elgadir MA, Salama M, Adam A. Anti-breast cancer from various natural sources, review. Int J Pharm Pharm Sci 2015;7:44-7.

12. Sakaeda T, Nakamura T, Okumura K. Pharmacogenetics of drug transporters and its impact on the pharmacotherapy. Curr Top Med Chem 2004;4:1385-98

13. Kuhad A, Chopra K. Curcumin attenuates diabetic encephalopathy in rats: Behavioral and biochemical evidences. Eur J Pharmacol 2007;576:34-42.

14. Yu HY, Lai YR, Kuo TL, Shen YZ. Effects of ethanol on pharmacokinetics and intestinal absorption of paraquat in animals. J Toxicol Sci 1994;19:67-75.

15. Kukan M. The isolated perfused liver as a tool in drug metabolism studies. In: Woolf TF, editor. Handbook of Drug Metabolism. New York: Marcel Dekker; 1999. p. 425-42.

16. Doluisio JT, Billups NF, Dittert LW, Sugita ET, Swintosky JV. Drug absorption. I. An in situ rat gut technique yielding realistic absorption rates. J Pharm Sci 1969;58:1196-200

17. Blanchard J, Tang LM, Earle ME. Reevaluation of the absorption of carbenoxolone using an in situ rat intestinal technique. J Pharm Sci 1990;79:411-4.

18. Yorgey KA, Pritchard JF, Renzi NL, Dvorchik BH. Evaluation of drug absorption and presystemic metabolism using an in situ intestinal preparation. J Pharm Sci 1986;75:869-72.

19. Azuma R, Hirota T, Manabe H, Komuro M, Kiwada H. First-pass of GTS-21 on canine gut wall and liver determined by portal-systemic concentration difference. Eur J Pharm Sci 2001;14:159-65.

20. Hashimoto Y, Sasa H, Shimomura M, Inui K. Effects of intestinal and hepatic metabolism on the bioavailability of tacrolimus in rats. Pharm Res 1998;15:1609-13.

21. Bahramsoltani R, Rahimi R, Farzaei MH. Pharmacokinetic interactions of curcuminoids with conventional drugs: A review. J Ethnopharmacol 2017;209:1-2.

22. Cho YA, Lee W, Choi JS. Effects of curcumin on the pharmacokinetics of tamoxifen and its active metabolite, 4-hydroxytamoxifen, in rats: Possible role of CYP3A4 and P-glycoprotein inhibition by curcumin. Pharmazie 2012;67:124-30.

23. Fleming I. Cytochrome p450 and vascular homeostasis. Circ Res 2001;89:753-62.

24. Hukkanen J, Pelkonen O, Raunio H. Expression of xenobioticmetabolizing enzymes in human pulmonary tissue: Possible role in susceptibility for ILD. Eur Respir J Suppl 2001;32:122s-6s.

25. Hukkanen J, Pelkonen O, Hakkola J, Raunio H. Expression and regulation of xenobiotic-metabolizing cytochrome P450 (CYP) enzymes in human lung. Crit Rev Toxicol 2002;32:391-411.

26. Gibbs MA, Hosea NA. Factors affecting the clinical development of cytochrome p450 3A substrates. Clin Pharmacokinet 2003;42:969-84.

27. Zhang W, Tan TM, Lim LY. Impact of curcumin-induced changes in P-glycoprotein and CYP3A expression on the pharmacokinetics of peroral celiprolol and midazolam in rats. Drug Metab Dispos 2007;35:110-5

28. Balabhaskar R, Kumar AR, Selvarajan S, Faridha A, Gunalan G. Potential natural products with anticancer properties and their applications. Asian J Pharm Clin Res 2019;12:27-33. 